\title{
Factors Influencing Curricular Reform; an Irish Perspective
}

\author{
Dr Helena Ferris ${ }^{1} \&$ Dr Pauline Joyce ${ }^{2}$ \\ ${ }^{1}$ Lecturer in Clinical Medicine, Trinity College Dublin, Ireland \\ ${ }^{2}$ Senior Lecturer at Institute of Leadership, Royal College of Surgeons in Ireland \\ Correspondence: Dr Helena Ferris, Lecturer in Clinical Medicine, Trinity College Dublin, Ireland. E-mail: \\ ferrish@tcd.ie
}

Received: January 28, 2015

Accepted: February 16, $2015 \quad$ Online Published: February 23, 2015

doi:10.5430/ijhe.v4n2p38

URL: http://dx.doi.org/10.5430/ijhe.v4n2p38

\begin{abstract}
There are various influences and obstacles when planning an educational curriculum. The imprint of globalisation on the landscape of Irish medicine highlights the importance of delivering a diverse curriculum with international dimensions so that knowledge and skills can transfer across borders. It is also clear that medical emigration has a negative impact on the delivery of services in Ireland and in maintaining a sustainable workforce. In addition, financial constraints will always play a role in the logistics of medical education and it is important that more cost effective virtual learning modules are incorporated into to the traditional classroom based approach.

Further research is needed into career satisfaction within medicine. One needs to try to understand what motivates doctors to stay within the Irish medical system, so that a curriculum with retention of graduates in mind can be designed. If a culture of education, guidance and support is fostered in our universities and hospitals, there is hope that a strong, competent and resilient breed of doctors will emerge to serve future generations.
\end{abstract}

Keywords: Medical education, Curriculum design, Globalisation, Medical emigration

\section{Introduction}

As the learning landscape continues to evolve, there are an increasing variety of influences that impact on planning educational programs. These tend to be dynamic and range from social and economic to environmental issues. The challenge lies in working with these multifactorial influences to design an adaptable curriculum that will prepare students for the $21^{\text {st }}$ century workplace.

This paper discusses the influences of globalisation on designing a curriculum, financial constraints surrounding the process, the impact of medical emigration, the increasing popularity of blended learning and the importance of flexible training. These influences are mainly explored in terms of how they pertain to workforce planning, with a focus on how we can empower the trainee to manage their own career advancement.

\section{Globalisation}

The debate surrounding the effects of globalisation is not a new one; however, there is a growing appreciation of its importance in our health care system and the need to manage it effectively. Globalisation has been defined by some as 'international integration' or 'the process of world shrinkage, of distances getting shorter and things moving closer' but practically it encompasses how we perceive ourselves and the world around us (Al-Rodhan N.R.F \& Stoudmann G. 2006)(Larsson, Thomas. 2001)(Lee K. 2003). The term 'Globalisation' is often misused and over used but the key discussion surrounding it is usually centred on the extent to which it is happening and whether the overall effect is positive or negative (Al-Rodhan N.R.F \& Stoudmann G. 2006)?

One may ask how globalisation is related to health? Perhaps we are more familiar with the term in relation to business and economics, but medicine truly embodies the principals of globalisation, as health issues traverse all borders. In ancient Greece, even the great father of medicine Hippocrates thought and travelled from his native Kos to at least as far as Turkey in a bid to strengthen and amalgamate medical knowledge (Margotta, Roberto. 1968). In a sense, globalisation has always existed and moved hand in hand with the evolution of human societies (Michael AJ. 2001). That said, the intensity and extent of modern day globalisation is unprecedented. For instance, there has been a $57 \%$ increase in students seeking education outside their home country from 1999-2010(Al-Rodhan N.R.F \& Stoudmann G. 2006). This poses modern medical educators with the unique challenge of making the curriculum 
more amenable to global practices so that doctors trained in one country can have a seamless transition into their own country.

In medical education today there are many challenges associated with the design of a balanced curriculum. These range from trying to incorporate vast advances in knowledge to increasing enrolments and advances in technology to satisfy 'generation Y'. Casting back to the early 1970's, Abrahamson aided this process by founding the concept of a curriculum as a living breathing entity. He felt that the curriculum should be dynamic and should vary with its participants, both lecturers and learners (Abrahamson S. 1978). Following on from this, it became evident that a curriculum cannot flourish unless it changes in response to the developing needs of its students, society and the economy. After all, the relationship between economic development and education is symbiotic (William J. Flynn \& Jeff Vredevoogd. 2010).

In recent years, much effort has been devoted to tailoring a curriculum that would prepare doctors to meet the health care needs of the $21^{\text {st }}$ century and the society it serves. Consultation with the stakeholders of medical training and medical education was the first step in this process. A report furnished by the Irish Medical Council and Medical Education and Training Board (MET) in 2012, showed that Ireland had the second largest proportion of internationally trained doctors in the world, with almost $35 \%$ of doctors registered in Ireland holding a basic medical qualification from outside Ireland. This imprint of globalisation on the landscape of Irish medicine shows the importance of delivering a diverse curriculum with international dimensions so that knowledge and skills can transfer across borders in almost an elastic fashion.

Several medical schools such as Trinity College Dublin (TCD) have incorporated a Global Health module into the medical curriculum in recent years. This module focuses on illnesses such as Malaria, TB etc. which are more prevalent outside of Ireland. The growing importance of Global Health has been further acknowledged by the appointment of a dedicated Senior Lecturer in Global Infection Diseases, who has created combined research activities between TCD and Uganda. Similarly, many universities have arranged a reciprocal short term clinical attachment for students in an international university of choice, as part of a scholarship initiative. The development of global health partnerships in this collaborative way helps young doctors to understand overseas medical issues and the importance of addressing local health disparities (Philpott, J. \& Batty, H. 2009).

It would be over simplistic for one to view globalisation as having a purely positive or purely negative effect on health care, when in reality it has both good and bad features. High income countries such as Ireland tend to focus on the perceived threat from low and middle income countries, of acquiring certain diseases such as HIV/AIDS, TB, Malaria, SARS etc. (Institutes of Medicine. 1997) Conversely, there is a tendency to overlook the benefits to high-income countries from population mobility when the migration of health professionals from poorer countries offers benefits to understaffed health systems in high-income countries (Collin J \& Lee K. 2003).

Since the end of the $19^{\text {th }}$ century, Irish doctors have been immigrating to countries outside of Ireland to practice medicine (Jones G. 2010). For instance, in many specialties, trainees are encouraged to carry out the fellowship years in America, Canada or Australia. The difficulty lies in that a large proportion of Fellows who train abroad do not return to Ireland. One can only speculate as to the reasoning behind this but the lack of consultant posts in University teaching hospitals and more humane working conditions abroad are a driving force. Ireland currently has the highest number of doctors working abroad, with $47.5 \%$ of our doctors outside the country (García-Perez AM, Amaya C \& Otero A. 2007). This statistic highlights how imperative it is that one strives to design a curriculum that encourages retention of medical graduates, if we are to sustain the future of the medical service.

\section{Medical Emigration}

Curriculum design has a key role to play in giving Irish doctors more job satisfaction and thus a more fulfilling career. As we have seen, the effects of disengagement are profound, as reflected in the number of graduates who emigrate aka the 'brain drain'. Medical emigration has contributed in turn to a shortage of specialists. Due to the current shortage of specialists, waiting lists are unacceptably long and can be up to 3 years following GP referral in some specialties. In an ideal training scenario, a robust curriculum would culminate in a certain career pathway. Unfortunately, this is not the case currently. Some $62 \%$ of doctors working in Ireland have completed their training within 10 years but only $16 \%$ of these are in a consultancy post (Howes J. 2012). In some medical and surgical specialties a large proportion of advertised consultancy posts remain vacant. This may be due to the dramatic drop in salary for these posts in Ireland secondary to the economic recession, unlike the income levels in the USA and Canada (Lavanya Chalikonda. 2013). These factors have made emigration more attractive and compound the need for a more globally aware curriculum that will prepare our doctors for an often, inevitable international career. 


\section{Financial Issues}

There are considerable financial implications to consider when designing a robust curriculum that is also transferrable internationally. It is estimated that the cost of college tuition doubles every nine years (FinAid. 2009). This coupled with the cost to the Health Service Executive of funding Specialist Registrar (SpR) training posts means that a bottle neck is created in the system. Ideally, more $\mathrm{SpR}$ places would be funded to allow 'protected teaching time' for the trainees. However, one is cognisant of the intense competition for attractive university hospital consultancy posts, so any increase would have to be off-set by an action plan to ensure employment for any additional SpR's.

Many hospital departments are embracing the cost benefit of globalisation to patient care and to the delivery of service. In some specialties, the effect of globalisation is very tangible with the outsourcing of X-ray analysis i.e. 'Tele Radiology' as well as remote transcription of doctor's notes. In modern medicine the patient is a consumer who expects excellent patient centred care but also cost effective health care. Many hospitals are now using a more cost effective international work force to do tasks such as those outlined above. The cost effective nature of patient care and service delivery in addition to the need for globalised medical education, is evident with well know American centres such as the Mayo Clinic and John Hopkins setting up hospitals in the middle east and Asia. Similarly, the Royal College of Surgeons in Ireland as a medical school in Bahrain, possibly in a bid to ensure that its high standards can be guaranteed abroad by having a physical presence in an international community.

A significant number of today's patients are so confident in premise of standardised medical care across the globe that 'medical tourism' has become a growing phenomenon. A recent report from Deloitte Consultancy estimates that the number of Americans travelling abroad for treatment will soar from 750,000 in 2008 to 10 million in 2012 with an estimated worth of $\$ 21$ billion (Robin Cooke. 2008). This has a significant financial implication for developing countries. Globetrotting patients seem to be reassured by the increased presence of accreditation in developing countries i.e. Joint International Commission and the rise in health care and medical education standards in general (Hodges B, Maniate J, Martimianakis M et al. 2005). Nevertheless, healthcare cannot be assumed to be the same as other basic goods such as food or alcohol (Kaul I, Grunberg I, Stern M. 1999). Linked to health care are many complex ethical, cultural, and human resource issues that we do not have time to explore in this paper.

As outlined so far, a dynamic curriculum that is receptive to global trends and needs is essential if we are to equip tomorrows' doctors with the right skills needed for the right patient population. However, a significant challenge to curriculum design in Ireland is the fact that undergraduate medical education in Ireland is underfunded, according to the Irish Medical Council (Review of Medical Schools in Ireland. 2003). As a result, huge emphasis is placed on attracting fee paying students. For example, in 2003 over $60 \%$ of medical school places were allocated to Non-EU students. Considering that the majority of Non- EU students return home to their native country, this practice gives them exposure and training to very high medical standards but this does not provide Ireland with a stable sustainable workforce. We have long known that we do not produce enough doctors for our own needs and the stark reality is highlighted in the Career Tracking Study which examined the factors affecting retention of Irish doctors. At the time of this study, over $40 \%$ of respondents were working abroad. Furthermore, there was evidence of long term or permanent emigration: $25 \%$ of graduates 25 years after graduation were still working overseas.

These frightening statistics highlight the urgency in developing a new framework for medical education in Ireland. Although there are many obstacles to doing so, I firmly believe that a curriculum which is more globally responsive would provide graduates with high quality schemes and clear career pathways, thus enabling a sufficient number of competent doctors to deliver patient centred care in Ireland.

\section{Digital Natives (Prensky, M. 2001)}

The medical education landscape is continuously evolving, as are the needs of the learner. During the past decade, many universities have reformed their undergraduate curriculum i.e. course content, teaching methods and examinations to try to meet the needs and expectations of generation Y (Heidi Lempp. 2004). Modern day students are information rich but time poor and are embracing informal ways of learning, with the help of technology, thus enabling them to take charge of their own development (Taylor E \& Sheehan T. 2011).

The Hidden Curriculum however, has rarely seen the same scrutiny. Having been unfamiliar with this phrase for most of my medical career to date, I am keenly aware of what it means in practice i.e. the unofficial rules for survival and advancement (Anna B. Reisman. 2006). At a post graduate level, time for formal learning is a luxury, as protected teaching time is often not afforded. The Buttimer Report in 2012 analysed the cost of providing protected teaching time for one half day a week for 2000 Non Consultant Hospital Doctors and estimated the cost at 
$€ 14,894,400$. The high cost involved in such an endeavour is appreciated; however, it is far less than the cost to the health service and the exchequer when almost $40 \%$ of doctors, whom the state has invested in, take their expertise to a more supportive foreign land.

A positive learning environment also needs to be fostered by medical departments. Currently, obtaining study leave to attend courses is becoming increasingly difficult. It is not surprising that there has been such an increase in demand for online education, so much so that University College Cork developed the first Masters program that is delivered in its entirety, online. With many SpR's wages and education grants being cut, online learning offers savings to the student as there are no accommodation or transport costs.

Increasingly, medical education is moving away from the passive and expensive classroom approach to a blended learning method of delivering educational programs. Particularly since the introduction of the European Working Time Directive, formal teaching time has decreased and an emphasis had been placed on substantial self-directed learning. By doing so, many institutions have adopted Vygotsky's 'Social Constructivism' approach to specialist education whereby we are given the scaffolding necessary to actively construct and refine our knowledge base while promoting independence and self-learning (Whitman N. 1993). As self-directed learners, trainees monitor and adjust their own learning and receive feedback to guide them in the right direction. With that said, that approach would not be possible were it not for online educational programs. Many popular educational websites have mobile friendly versions so that an 'anytime, anywhere' approach can be adopted. Research endeavours are also strongly encouraged so that the critical thinking skills and ability to make sound judgements based on knowledge are also fostered. The Hunt Report in 2011 also supported the idea of creating an environment that has up to date knowledge, practices and research (Hunt. 2011).

As we have discussed, there are multiple challenges to designing a well-rounded curriculum that appeals to all learning styles. To overcome these barriers, learning is becoming increasingly blended, customised to the organisation and self-managed (Taylor E \& Sheehan T. 2011). In doing so, we draw upon technology to empower each individual learner (Larson MJ, Amodeo M, Storti SA et al. 2009).

\section{Flexible Training}

As discussed so far, the student body of today is rich and diverse in terms of being culturally varied and technologically savvy but there is also a steady increase in the age of the student body. According to the National Centre for Education Statistics (NCES), there has been a 13\% increase in enrolment in students aged over 25 between 1995 and 2006 (Boggs G. 2010). This brings to the fore issues surrounding flexible training to facilitate family care and a healthier work life balance. A conflict arises when you consider that medicine truly is a vocation which demands self-sacrifice; often to the detriment of one's relationships and family life. It is no secret that doctors have an unacceptably high level of marital breakdown and substance abuse due to the unrealistic pressures and expectations imposed upon them. It is imperative that we strive to develop new curricula which teach doctors to cope with the stresses of their chosen career and give them the tools to look after themselves and their colleagues.

In 1984 Zigmond discussed the concept of 'the paradox of the wounded healer' (Zigmond D. 1984). Many physicians today are struggling with work life balance and females in particular are facing insurmountable barriers when it comes to combining a career in medicine with family life. Considering approximately $62 \%$ of the medical work-force is female, we need to design flexible training schemes and curricula, which allow doctors in training to live a full life outside of medicine. This feeling was reiterated in a recent study of Specialist Registrars in Paediatrics, which reported that $35 \%$ of females desired flexible training and $43.5 \%$ desired flexible consultancy. Interestingly, the Career Tracking Study of 2005 showed that only $\sim 8 \%$ of graduates were working less than full time, almost all of whom were female and $72 \%$ of whom were in either in General Practice or Public Health. Owing to the practical difficulties associated with taking time out of a scheme to have a family, many doctors opt to wait until after their training scheme to start a family. However, as the age at which students begin a career in medicine continues to rise, many women may not have the luxury of time. I believe that the working environment would be enhanced if part time training was encouraged and if simple steps such as having a crèche on the hospital grounds existed. If graduates were mentored and supported then more graduates would be retained in the Irish health care system.

\section{Conclusion}

It is evident that there are various influences and obstacles when planning an educational curriculum. As discussed, the imprint of globalisation on the landscape of Irish medicine highlights the importance of delivering a diverse curriculum with international dimensions so that knowledge and skills can transfer across borders. 
It is clear that medical emigration has a negative impact on the delivery of services in Ireland and in maintaining a sustainable workforce. In addition, financial constraints will always play a role in the logistics of medical education and it is important that more cost effective virtual learning modules are incorporated into to the traditional classroom based approach.

Further research is needed into career satisfaction within medicine. One needs to try to understand what motivates doctors to stay within the Irish medical system, so that a curriculum with retention of graduates in mind can be designed. If a culture of education, guidance and support is fostered in our universities and hospitals, there is hope that a strong, competent and resilient breed of doctors will emerge to serve future generations.

\section{References}

A Career Tracking Study entitled "Factors affecting Career Choices and Retention of Irish Medical Graduates". Commissioned by the MET Group, and undertaken by the Department of Public Health Medicine and Epidemiology, University College 2005. http://www.hrb.ie/fileadmin/Staging/Documents/RSF/PEER/Policy_Docs/Relevant_reports/buttimer.pdf

Abrahamson S. (1978). Diseases of the curriculum. J Med Educ. 1978 Dec;53(12):951-7.

Al-Rodhan N.R.F \& Stoudmann G. (2006). Definitions of Globalization: A Comprehensive Overview and a Proposed

Definition. http://www.academia.edu/2969717/Definitions_of_Globalization_A_Comprehensive_Overview_and_a_The_In ternational_Relations_and_Security_Network_ETH_Zurich_June_19_2006.

Anna B. Reisman. (2006). Outing the Hidden Curriculum. The Hastings Center Report. 2006;36(4):9. http://dx.doi.org/10.1353/hcr.2006.0065

Boggs G. (2010). Democracy's College: The evolution of the community college in America. National Centre for Education Statistics. http://www.aacc.nche.edu/AboutCC/whsummit/Documents/Combined_Issue_Papers.pdf

Collin J \& Lee K. (2003). Globalisation and trans-border health risk in the UK. Case studies in tobacco control and population mobility. London: The 2003. http://www.socialpolicy.ed.ac.uk/_data/assets/pdf_file/0003/58737/Globalisation_and_Transborder_health_ris k_in_the_UK.pdf

David Zigmond. (1984). Physician heal thy self, the paradox of the wounded healer. http://www.marco-learningsystems.com/pages/david-zigmond/n30.7.14_physician-heal-thyself.pdf

Dr. Asam Ishtiaq. International Health Care Workers, The Irish Perspective. Irish Medical Organisation. https://www.iom.int/jahia/webdav/site/myjahiasite/shared/shared/mainsite/microsites/IDM/workshops/mhrh232 40306/presentation_ishtiaq.pdf

FinAid. (2009). Tuition Inflation. Retrieved October $28^{\text {th }} 2009$ www.finaid.org/savings/tuition- inflation.phtml.

García-Perez AM, Amaya C \& Otero A. (2007). Physicians' migration in Europe: an overview of the current situation. BMC Health Serv Res. 2007;7:20. http://dx.doi.org/10.1186/1472-6963-7-201

Heidi Lempp. (2004). The hidden curriculum in undergraduate medical education: qualitative study of medical students' perceptions of teaching. BMJ 2004;329:770. http://dx.doi.org/10.1136/bmj.329.7469.770

Hodges B, Maniate J, Martimianakis M et al. (2005). Cracks and crevices: Globalisation discourse and medical education. Medical Teacher 2009; 31:910-917.

Howes J. (2012). Recruitment into specialty training in 2013. BMJ Careers 2012; http://careers.bmj.com/careers/advice/view-article.html?id=20009204

HSE. Supplementary Report. Ireland: Health Service Executive. (2012). Available from:http://www.hse.ie/eng/services/Publications/

Hunt. (2011). National Strategy for Higher Education to 2030 - Report of the Strategy Group. Department of Education www.hea.ie/sites/default/files/national_strategy_for_higher_education_2030.pdf

Institutes of Medicine. (1997). America's vital interest in global health. Washington, DC: National Academy Press, 1997 http://www.nap.edu/openbook.php?record_id=5717

Jones G. (2010). 'Strike out Boldly for the Prizes that are Available to You': Medical Emigration from Ireland 1860-1905. Med Hist. 2010;54(1):55-74. http://dx.doi.org/10.1017/S0025727300004312 
Kaul I, Grunberg I, Stern M. (1999). Global Public Goods. New York and Oxford: Oxford University Press; 1999 http://web.undp.org/globalpublicgoods/TheBook/globalpublicgoods.pdf

Larson MJ, Amodeo M, Storti SA et al. (2009). A Novel CBT Web Course for the Substance Abuse Workforce: Community Counselors' Perceptions. Substance Abuse 2009;30(1):26-39. http://dx.doi.org/10.1080/08897070802611741

Larsson, Thomas. (2001). The Race to the Top: The Real Story of Globalization Washington, D.C.: Cato Institute. p. 9. ISBN 978-1930865150 http://en.wikipedia.org/wiki/Globalization

Lavanya Chalikonda. (2013). Why are Irish doctors emigrating? Royal College of Surgeons in Ireland Student Medical Journal 2013; 6(1): 93-8.

Lee K. (2003). Globalization and Health, An introduction. London, Palgrave Macmillan. ISBN 0-333-79483-4 (242 pp). http://dx.doi.org/10.1057/9781403943828

Lee K. (2004). Globalisation, what is it and how it affects health? Med J Aust 2004; 180 (4): 156-157.

Luis C. Moll. (2013). L.S. Vygotsky and Education (Routledge Key Ideas in Education) Paperback - July 18, 2013

Margotta, Roberto. (1968). The Story of Medicine, New York: Golden Press.

Masters in Public Health Online. http://www.ucc.ie/en/epid/postgrad/mphonline/

Medical Graduates of the National University of Ireland in 1978: Who and where are they?; Finucane, Loftus, O’Callaghan;Irish Medical Journal, January 2005, Vol. 98, No. 1; www.imj.ie

Medical workforce intelligence report. Irish Medical Council. (2012). http://www.medicalcouncil.ie/News-and-Publications/Publications/Annual-Reports-Statistics-/Medical-workfor ce-intelligence-report-.pdf

Michael AJ. (2001). Human frontiers, environments and disease. Cambridge: Cambridge University Press, 2001. http://dx.doi.org/10.1017/CBO9781139106924

Philpott, J. \& Batty, H. (2009). Learning best together: social constructivism and global partnerships in medical education. Medical Education, 43: 923-924. http://dx.doi.org/10.1111/j.1365-2923.2009.03436.x

Prensky, M. (2001). Digital Natives, Digital immigrants. http://www.marcprensky.com/writing/Prensky\%20-\%20Digital\%20Natives,\%20Digital\%20Immigrants\%20-\%2 0Part1.pdf

Review of Medical Schools in Ireland. (2003). Irish Medical Council. https://www.medicalcouncil.ie/News-and-Publications/Publications/Education-Training/Review-of-Medical-Sc hools-in-Ireland-2003.pdf

Robin Cooke. (2008). Operating profit. Why put up with expensive, run-of-the-mill health care at home when you can be treated just as well abroad? The Economist, Aug 14th 2008. http://www.barfooinc.net/drupal6.0/sites/default/files/Globalisation\%20and\%20health\%20care\%20\%20Operati ng\%20profit\%20\%20Economist.pdf

Taylor E \& Sheehan T. (2011). Prespectives on future of learning. Ashridge Business School. Accessed 05/09/11 from www.ashridge.org.uk.

Van Niekerk JP, Christensen L, Karle H, Lindgren S, Nystrup J. Report: WFME Global Standards in Medical Education: Status and perspectives following the WFME World Conference. Med Educ 2003; 37: 1050-1054. http://dx.doi.org/10.1046/j.1365-2923.2003.01679.x

Whitman N. (1993). A review of constructivism: understanding and using a relatively new theory. Fam Med.1993 Sep;25(8):517-21.

William J. Flynn \& Jeff Vredevoogd. (2010). The Future of Learning: 12 Views on Emerging Trends in Higher Education. Planning for Higher Education. 38(2): 5-10. 